schaft für Geburtshülfe (s. den Sitzungsbericht: Monatsschrift für Geburtsk., September 1869 , S. 162) mitgetheilten zeigt, in welchem die Section den betreffenden Nachweis lieferte, zweille ich kaum, dass anch in dem meinigen ein kleiner Theil von Eisenlösung durch eine der Muttertrompeten in die Bauchhöhle gedrungen ist, und die gefahrdrohenden Symptome veranlasst hat. Da indess die physikalischen Erscheinungen einer Peritonitis nicht entschieden waren, muss die Diagnose zwischen dieser und einer heftigen Endometritis zweifelhaft bleiben.

In jener Sitzung der Gesellschaft für Geburtshülfe (s. o.) sind die Intrauterininjectionen ausfithrlich nach verschiedenen Gesichtspunkten beleuchtet worden, und ich will deshalb, da ich nichts Neues darïber zu sagen weiss, nur noch wiederholt vor dieser Operation bei Knickungen der Gebärmutter warnen. [Wenigstens soll man sie nicht ohne vorherige Dilatation machen. Red.]

\title{
Zur Sehwangersehaftsdaner.
}

\author{
Von
}

Dr. Wallichs in Neumünster.

In dem oben eitirten Heft der Monatsschrift (September 1869) handelt Ahlfeldt in Leipzig über die Dauer der Schwangerschaft. Zuverlässige Angaben über einzelne Fälle sind bekanntlich selten; - da mir nun eine Beobachtung zu Gebote steht, die, weil sie sich an derselben Frau wiederholt, einiges Interesse beanspruchen kann, will ich sie hier mittheilen.

Rine damals 37 Jahre alte Frau, die vorher fünf Mal geboren und ein Mal abortirt hatte - ihre Menstruationsepochen währten $32-35$ Tage, ïber die früheren Schwangerschaften sind betreffs der Dauer keine genauen Daten vorhanden - , war am 30. oder 31. Juli 1865 zuletzt menstruirt, am 4. August fand der befruchtende Coitus statt, sie gebar am 30. April 1866, also am 269. Tage nach der Empfängniss.

Nachdem ein Abort, uiber den ich das Genauere nicht mehr weiss, inzwischen vorgekommen war, hatte diese Frau den letzten 
Hartmann, Nachtrag über persistirende Vasa omphalomesaraica. 163

Tag ihrer Menses am 13. October 1867, - am 16. October Coitus, Geburt am 11. Juli 1868, also wiederum 269 Tage nach der Empfängniss.

Beide Kinder waren reif und gesund, das erste ein Mädchen, das zweite ein Knabe. Auf sämmtliche obige Daten ist genau geachtet worden, der Beischlaf ward nicht an einem dem genannten nahen Tage ausgeübt, und die Angaben sind absolut zuverlässig.

Wahrscheinlich hat eine erneute Schwangerschaft derselben Frau wieder eine ganz gleiche Dauer gehabt, doch ist der Tag der Befruchtung nicht mit derselben Sicherheit anzugeben. Am 29. Januar 1869 traten die Menses ein, acht Tage nach dem Aufhören derselben hat ein Beischlaf stattgefunden, die Geburt eines reifen Knaben erfolgte am 5. November 1869. Wenn nun die befruchtende Cohabitation am 9. März, zwölf Tage nach dem Beginne der Menstruation, ausgeführt ward, was wahrscheinlich ist, so hat auch diese Schwangerschaft (die zehnte, mit Einschluss von zwei nicht vollendeten) 269 Tage gedauert.

\section{Nachtrag über persistirende Vasa omphalomesaraica}

ron

Dr. G. Hartmann in Stuttgart.

Als nachträglichen Zusatz zu meinen Beobachtungen über die oben genannten Gebilde (siehe Monatsschrift f. Geburtskunde Band XXXIII. S. 193) möchte ich mir zwei Bemerkungen erlauben: über die Häufigkeit des Vorkommens nämlich und über einen früheren Beobachter derselben.

Was zunächst ihre Häufigkeit anlangt, so* habe ich nummehr unter circa 800 Nachgeburten neun Fälle gefunden, was, wenn ich auch die beiden ersten als ganz zufällige Erfunde weglasse, immer noch einer Frequenz von beinahe 1 Proc. entspricht, so dass es eigenthümlich erscheint, dass nicht auch anderen Forschern diese Gebilde häufiger aufstossen. Zu einiger Erklärung dieser Factums kann ich übrigens beifügen, dass es zur Auffindung der genannten Gefässe ganz unumgänglich nothwendig ist, die Nachgeburten ganz frisch zu untersuchen, da durch die allgemeine blutige Imbibition der Eihuillen, 